\title{
PERFECTIONISM, MOOD STATES, AND COPING STRATEGIES OF SPORTS STUDENTS FROM BULGARIA AND RUSSIA DURING THE PANDEMIC COVID-19
}

\author{
Tatiana Iancheva ${ }^{1}$, Liudmila Rogaleva ${ }^{2}$, \\ Alejandro García-Mas ${ }^{3}$, Aurelio Olmedilla ${ }^{4}$ \\ 'National Sports Academy "Vassil Levski”, Sofia, Bulgaria; \\ ${ }^{2}$ Ural Federal University, Yekaterinburg, Russia; \\ ${ }^{3}$ Department of Psychology, University of the Balearic Islands, Spain; \\ ${ }^{4}$ Department of Personality, Evaluation and Psychological Treatment, \\ Faculty of Psychology, University of Murcia, Spain
}

\section{ORCID (19)}

Tatiana Iancheva https://orcid.org/0000-0001-9718-6056

Liudmila Rogaleva https://orcid.org/0000-0002-6870-9409

Alejandro García-Mas https://orcid.org/0000-0001-8718-9456

Aurelio Olmedilla https://orcid.org/0000-0002-2389-0515

\begin{abstract}
The pandemic COVID-19 constituted one of the greatest ordeals the world has seen in the last decades. Social isolation has changed athletes' lives completely and brought a number of consequences - both technical and psychological.

The aim of this study was to investigate the dominant psychic conditions and perfectionism and their relation to the preferred coping strategies during the pandemic COVID-19 among sports students from Bulgaria and Russia and to outline their specificity depending on their gender, kind of sport, qualification, and nationality.

The research was done among 199 sports students from Bulgaria and Russia who practice 18 kinds of sport, aged between 16 and 32 years, divided into groups according to their gender, kind of sport, level of qualification, nationality.

The research methods included: 1) Sociodemographic, personal and sports evaluation; 2) Multidimensional Perfectionism Scale (FMPS, Frost, Marten, Lahart \& Rosenblate, 1990), adapted for Bulgarian conditions by T. Iancheva, 2009; 3) Profile of Mood States (McNair, Lorr, \& Droppleman, 1971); 4) Approach to Coping in Sport Questionnaire (ACSQ-1; Kim 1999; Kim \& Duda, 1997).

There are significant differences depending on gender, kind of sport, qualification, and nationality. The specific role of adaptive and maladaptive perfectionism was viewed in relation to the dominant psychic conditions during social isolation and the preferred coping strategies.
\end{abstract}

Key words: Perfectionism, Mood States, coping strategies, COVID-19, sports students

\section{INTRODUCTION}

In the last few months, the world has faced a serious ordeal it was not prepared for - the pandemic COVID-19. It quickly spread all over the world and gave rise to a great deal of fear, anxiety, and worries. The life of millions of people all over the world has changed. This requires adaptation and coping with the situation despite the uncertainty about its duration and nature. The World Health Organiza- 
tion provided some guidelines related to the management of the problem both from biomedical and psychological viewpoint. At this stage, people are fully aware of the importance of preventive and medical actions. However, the necessity of urgent psychological interventions with people diseased with COVID-19 are becoming much more critical.

As regards social psychic health, the major psychological consequences now are related to increased stress, anxiety, and depression. The implementation of anti-epidemic measures, especially the lockdown and its impact on the everyday activities and social contacts, will lead to an increase in the level of loneliness, depression, and detrimental drug and alcohol abuse.

Each threatening, uncertain and risky situation brings about tension and stress. People experience different fears: fear of death, fear of getting diseased, uncertainty about the symptoms and the way of contracting the disease and in this relation they avoid hospitals, develop fear of losing their jobs, of social exclusion/lockdown, of being associated with the disease (e.g. aggression against people living in diseased areas). They also experience a feeling of futility in protecting close people, a fear of losing them, a separation from relatives due to lockdown, boredom, loneliness, and depression because of the isolation, etc. These fears are greatly influenced by mass media and especially by social networks. In a video message the Head of UN emphasized on the psychological problems such as depression and loneliness as "being the biggest causes of unhappiness nowadays".

The pandemic COVID-19 has affected all the activities and, in many areas, completely discontinued them. The field of sport, especially elite sport, is one of the most affected. The business model of sport is seriously disrupted and threatens the normal functioning of most kinds of sport.

The most serious blow for sport is indisputably the cancellation of the most significant sports event - the Summer Olympic Games in Tokyo, 2020. So far, only the World Wars and a few politically based riots have prevented several nations from participating in the Olympic Games. The pandemic COVID-19 has also led to cancellation of the entire sports calendar both internationally and nationally - world and continental championships, world cups, Olympic qualifications, international tournaments, and so on. Each part of the chain of sports activities has been affected - athletes, teams, coaches, sports-technical personnel, leagues, media, business, sports education. While the restrictions to the unorganized sport are gradually abolished, elite sport faces extremely serious challenges both sports-technical and, maybe in a greater extent, psychological. The uncertainty the future holds, the lack of definite reference points about the way of preparation and forthcoming competitions, the fear of travelling and related to it risks of infection, the possible competitions without audience, the danger of overall restructuring of sports life and others are a premise for increasing stress, for problems related to motivation and choice of coping strategies, emotional reactions, etc. COVID-19 has influenced athletes and sports organization in different ways. There are understandable problems related to the uncertainty and anxiety about the period of qualifications, the planning of preparation in conditions of uncertainty and the lack of information about the future sports calendar, about keeping top sporting shape. This leads to a number of psychological consequences for athletes: fear they will be less physically prepared for future competitions, for being in a less advantageous position than their rivals. They do not know what they will do if the 
Olympic Games are cancelled again, whether they will continue their sports career, how they will cope with social isolation imposed in their current preparation, how they will keep their motivation.

Athletes' life is connected with high activity, constant travelling, intense emotions, numerous communications. Self-isolation, being a consequence of the imposed lockdown, on the one hand is vital, related to preserving athletes' health and life, but on the other hand - it can lead to a number of negative psychological effects - depression, increased anxiety, aggressive reactions, risky behavior, and so on.

The application of adequate psychological interventions aiding athletes requires an objective analysis, based on real experimental data - what are the real consequences for athletes with different level of qualification, how do they cope with the current situation? This requires research aimed at different groups (Arden, \& Chilcot, 2020).

The analysis of the scientific publications about psychological consequences of selfisolation in conditions of pandemic shows that they are still few but research on these problems is being actively carried out in the scientific platforms Frontiers and Frontiers in psychology, in a special section Coronavirus Knowledge Hub.

We can outline several directions of research on this problem.

MacIntyre, Green, Beckmann, Lane, Vaughan, Morris, Murphy, Kenttä, Raalte, Calogiuri study The Effects of the Covid-19 Pandemic on Sport: Mental Health Implications on Athletes, Coaches and Support Staff. The authors view the cancellation of the Olympic and Paralympic Games in Tokyo, 2020 and the European Football Championship as a result of the pandemic COVID-19. They emphasize on the restrictions regarding travelling, physi- cal activity, and mass gatherings and the serious consequences for athletes - a restricted access to training sessions, cancellation of competitions, and financial problems. These consequences can lead to serious psychological problems. Taking into account the scale of this pandemic for humankind and athletes from all countries, the authors believe that the strategies that could help athletes to cope with the arising difficulties should be studied. The surveys are related to the analysis of the psychological aspects of athletes' behavior in conditions of self-isolation - regulation of emotions, overcoming stress, stability, psychic health and wellbeing.

The surveys in this direction aim at stimulating new scientific notions and viewpoints about the extent to which athletes, coaches, managers, specialists and major interested parts are ready to evaluate the current situation, how they cope and see the way out of it, what policies in the field of sport should be taken, how they can educate themselves in effective management of their psychic health. The authors pose the issue about athletes being role models and motivators in times of the pandemic COVID-19, as well as about the intercultural comparisons in the reactions in the emergency situation with COVID-19 and its overcoming.

Sokolowska, Ayton and Brandstätter (2020) researched Coronavirus Disease (COVID-19): Psychological Reactions to the Pandemic. The authors highlighted the significant economic and social stress and the extraordinary opportunity to gather scientific knowledge about various aspects of human behavior, knowledge and emotions which could help in the understanding and analysis of human reactions to the pandemic COVID-19 and to prepare people for reacting in future pandemics. The authors' idea is to stimulate research emphasized on knowledge regarding 
the perception of risk and uncertainty related to pandemic, the role of social influence, behavior, emotions, stress, overcoming, wellbeing and social trust, emotional reactions of socializing. The authors welcome the resurveys of both personal and individual differences, as well as the multinational and multicultural ones.

The third line of research is directed towards Coronavirus Disease (COVID-19): Psychoeducational Variables Involved in the Health Emergency (De la Fuente, Kauffman, Dempsey, Kauffman, 2020). The authors draw the attention to the different behavior changes in the organization of our personal, family, and academic life during COVID-19 and the necessity of adaptation of teachers, students, and family members.

Part of the research is aimed at surveying the issues of psychic health.

Wang, Wang, Yang (2020) pointed out that COVID-19 not only affects the physical health of Chinese people, but also their psychological health. This article mainly summarized the causes, clinical manifestations and preventive measures of COVID-19 impact on psychology of Chinese people and presented two representative cases at the same time.

Forty-three experts in the field of social sciences and behavior (Van Bavel, Baicker, Boggio, Capraro, et al., 2020) pay attention to the significance of the research and the unification of the efforts in studying the consequences of pandemic on people's behavior. The authors see the topicality of the research on the subject also in relation to helping the policies, leaders and community in managing the threat, the orientation in different social and cultural context, the improvement of scientific communication, the unification of individual and group interests, the use of efficient leadership, and the provision of social and emotional support.
Schinke, Papaioannou, Henriksen, $\mathrm{Si}$, Zhang, \& Haberl (2020) point out that COVID-19 has changed our life as citizens and has posed a lot of problems and possibilities related to sports indicators, physical activity and health to sports psychologists. The authors emphasize on counsellors' activity, especially those working with future Olympic contenders. They draw the attention to the necessity of developing strategies for efficient work in conditions of social isolation, danger of career collapse, uncertainty, nontraditional and restricted access to effective training environment. These strategies should be based on athletes' health and wellbeing in their aspiration for perfection, considering the cultural context. The authors say that we should consider three periods of time: a) until the time the Olumpic Games were postponed; b) after they were rescheduled for 2021 , and c) the way leading to Tokyo, 2021 and the related psychological problems and life plans changes. They mention some reactions to stress such as problem sleeping, reduction of appetite, disappointment, loneliness, and fear that the future uncertainty could lead to losing the Olympic 'moment'.

Some authors (Zhou, et al., 2020) analyze the emotions and coping strategies used by people in times of pandemic.

The meta-analysis shows that people's turning to fear leads to changes in their behavior, if they are capable of coping with the threat. However, this could also lead to protective reactions when people feel helpless in their actions.

Emotions often lead to perceiving risk as a greater threat than it actually is (Peters, Lipkus, \& Diefenbach, 2006). In case of strong emotional reactions, people can ignore both important information and the probability and scale of the problem.

The fear of a disease is related to a higher 
level of egocentrism, bigger fear, and supposed threat connected with intolerance to external groups (Feldman \& Stenner, 1997; Marcus, Sullivan, Theiss-Morse, \& Wood, 1995).

The topic about stress and its overcoming is especially important, even in the places where the virus has not spread yet. Pandemic is a major stressor related to chaotic anxiety and economic difficulties.

Jetten, Haslam, \& Haslam (2012) think that social isolation and loneliness increase stress and have a detrimental effect on psychic health, cardiovascular system, and immunity.

Some surveys show that forced proximity can be a factor for increasing the risk of aggression (Ellemers, \& letten, 2013) and violence in families (Greenaway, Jetten, Ellemers, \& Van Bunderen, 2015; Owen, 2020).

In the face of global pandemic it is impossible to avoid stress but the knowledge about it gained in the last twenty years and the surveys on stress coping strategies show that it is not the type and level of stress but the way of thinking and the evaluation of a stressful situation that determines and changes its influence (Jamieson, Crum, Goyer, Marotta, \& Akinola, 2018). Numerous studies reveal that the stimulation of adaptive way of thinking about stress can enhance positive emotions, reduce negative health symptoms, and improve physiological functioning in conditions of acute stress (Crum, Akinola, Martin, \& Fath, 2017; Crum, Salovey, \& Achor, 2013).

People experience an array of strong emotions in response to negative life events. To cope with these emotions, they use different behavior and cognitive strategies. Proneness to inadequate and risky behavior and its consequences in situations of uncertainty, threat, and risk, make researchers study their relation to different coping strategies.

Coping strategies are defined by many scientists as a complex, dynamic, multidimensional process (Crocker \& Graham, 1995; Crocker \& Isaak, 1997; Eklund, Gould \& Jackson, 1993; Gould, Udry, Bridges \& Beck, 1997). Coping aims at regulating emotions and changing behavior so that we can do better in a particular situation. Coping with a situation requires a change in people's behavior and/or cognitions so that they can manage the situation better. Coping is defined as "a process of constantly changing cognitive and behavior efforts to manage specific inner and/or outer requirements or conflicts, determined as exceeding one's own resources" (Lazarus \& Folkman, 1984), such as an individual's efforts to manage psychological stress related to harmful, threatening or challenging situations (Lazarus, 1999). Coping is a response to the perception of threats which appear in the environment. Most authors are unanimous that coping consists of conscious psychological and psychic efforts aimed at improvement of our own resourcefulness when dealing with stressful events or at a decrease in the outer pressure (Anshel, 1990; Anshel, et al., 2001; Yancheva, Domuschieva - Rogleva, 2012; Domuschieva - Rogleva, Iancheva, 2017). Implementation of certain coping strategies supposes awareness that the problem or situation are problematic ones.

Perfectionism is an important psychological variable affecting the way an athlete's cognitive, affective, and behavior characteristics function (Davis, 1997; Frost, Heimberg, Holt, Mattia, \& Neubauer, 1993, Hamashek, 1998; Terry-Short, Owens, Slade, \& Dewey, 1995). It is defined as a net of cognitions including expectations, interpretation and evaluation of events (Burns, 1980), such as "setting unrealistically high standards, accompanied by overcritical self-assessment" (Frost, Marten, Lahart \& Rosenblate, 1990). Perfectionism is related to orientation to 
higher goals and more successful performance (Bradham, 2000).

In sport the approach towards perfectionism is known to be a multidimensional construct with 6 components: personal standards, concern over mistakes, parental expectations, parental criticism, doubts about actions, organization.

The empirical studies reveal that concern over mistakes, parental criticism, parental expectations and doubts about actions are subscales related to non-adaptive functioning (Enns \& Cox, 2002). Conversely, the surveys support the functional nature of the subscales: personal standards and organization.

High personal standards are adaptive when combined with low levels of concern over mistakes, parental expectations and criticism (Parker, 1997). Conversely, high personal standards can be non-adaptive when related to high levels of concern over mistakes, parental expectations and criticism (Hall, et al., 1998).

The theory of self-determination connects the changes in perfectionism with the effective coping (Deci \& Ryan, 2000).

Knowledge about the specific cognitive and behavior coping strategies used by athletes in the current situation, as well as the evaluation of their efficiency, can help psychologists, coaches and athletes to a great extent in their looking for the most adequate decisions of the raised psychological problems and to provide guidance for changes in the direction of the actions taken.

The aim of this study was to investigate the dominant psychic conditions and perfectionism and their relation to the preferred coping strategies during the pandemic COVID-19 among sports students from Bulgaria and Russia and to outline their specificity depending on gender, kind of sport, level of qualification, and nationality.

\section{MATERIALS AND METHODS \\ Participants}

The research was done among 199 sports students aged between 16 and 32 years. For the purposes of the research the participants were divided into groups according to their gender (100 men and 99 women), kind of sport (rhythmic gymnastics, athletics, football, orienteering, tennis, taekwondo, basketball, volleyball, wrestling, sports shooting, skiing, weightlifting, cycling, ice hockey, sports dancing, badminton, triathlon, equestrian), level of qualification (competing in: university and regional competitions, national championships, international competitions, qualified for the Olympic Games in Tokyo, 2020), nationality (sports students from Bulgaria - 95, from Russia -78 , foreign students studying in Bulgaria and Russia - 26).

The survey was carried out online in Bulgaria and Russia over the period 13-30 April 2020 in conditions of emergency situation in relation to the pandemic COVID-19 in the two countries. All subjects were studying online in this period.

At the beginning of the research all participants were informed about the aim of the survey and their consent was obtained.

This research is part of an international survey initiated by Alejandro García-Mas, Department of Psychology, University of the Balearic Islands, Spain and Aurelio Olmedilla Department of Personality, Evaluation and Psychological Treatment, Faculty of Psychology, University of Murcia, Spain.

\section{Instruments}

In order to fulfil the aim of the research we used complex methods including:

1. Sociodemographic, personal and sports evaluation. An ad hoc questionnaire was created, based on the injury protocol (Olmedilla, García-Montalvo \& Martínez-Sánchez, 2006; 
Olmedilla, Rubio, Ortega, \& García-Mas, 2017) used by Aurelio Olmedilla at the Murcia High Performance Center. This questionnaire allows evaluating sociodemographic, personal and sports data (age, sex, place of residence, people you live with, sport, studies you attend and course and whether you take classes online).

2. Multidimensional Perfectionism Scale (FMPS, Frost, Marten, Lahart \& Rosenblate, 1990), adapted for Bulgarian conditions by $\mathrm{T}$. Iancheva, 2009. This scale provides six subscales: Personal Standards (PS), Concern over Mistakes (CM), Parental Expectations (PE), Parental criticism, Doubts about actions (DA), and Organization $(O)$.

3. Profile of Mood States (McNair, Lorr, \& Droppleman, 1971) was used in its Spanish adapted and validated version by Fuentes, Balaguer, Meliá and García-Merita (1995). The short scale contains 29 items answered on a 5-point scale. In this version the athletes report on their own mood state in relation to each of the items on the instrument. The scale reports five moods: tension, anger, vigor, fatigue and depression.

4. Approach to Coping in Sport Questionnaire (ACSQ-1; Kim 1999; Kim \& Duda, 1997) was used in its Spanish version (Kim, Duda, Tomás, \& Balaguer, 2003). This scale contains 28 items answered in Likert type from 1 (never) to 5 (always). The questionnaire aims to find out how often the athlete uses certain coping strategies in competitive situations. The five dimensions of coping assessed are: emotional calming (7 items; e.g., "I tried to block negative thoughts"), active planning/cognitive restructuring (6 items; e.g., "I tried to find something positive in what happened"), mental withdrawal (6 items; e.g., "I thought there was nothing to be done, and I accepted it"), seeking social support (4 items; e.g., "I talked to someone to figure out what
I could concretely do to solve the problem") and behavioral risk (5 items; e.g., "I was constantly changing strategy").

\section{Statistical Analysis}

In order to process the initial data from the research we used the statistical program SPSS 21 , and did an alternative analysis (to establish the relative shares of different responses in the questionanires, as well as to process the personal information such as gender, age, qualification, etc.), correlation analysis, comparative analysis (U-criterion of Mann-Whitney and Criterion of Kruskal-Wallis), and step regression analysis.

\section{RESULTS AND ANALYSIS}

Table 1 shows the results obtained from descriptive statistics.

The analysis of the results from our survey revealed that the Adaptive Perfectionism is domineering among the students we researched (Table 1). The subscales Organization $(\mathrm{M}=4.03)$ and Personal Standards $(\mathrm{M}=3.22)$ received the highest results, and $\mathrm{Pa}$ rental criticism $(\mathrm{M}=1.95)$ and Concern over Mistakes $(\mathrm{M}=2.41)$ - the lowest.

The results from our research on the dominant Mood States during the last week (during the emergency situation because of the pandemic COVID-19) revealed (Table 1) that the pandemic and social isolation did not have a strong negative impact on the mental state of the studied athletes. The highest values were received for Vigor $(\mathrm{M}=3.28)$. Despite the imposed lockdown and the related isolation, the researched athletes felt quite energetic, alert and motivated. Next subscale was Tension $(\mathrm{M}=2.26)$, i.e. despite being relatively vital and energetic, the researched sports students experienced nervousness, anxiety, excitement. The fact that Depression $(\mathrm{M}=1.67)$ received the lowest values is favorable. 
Table 1. Descriptive statistics of studied variables

\begin{tabular}{lccccc}
\hline & N & Mean & SD & Min & Max \\
\hline Concern over Mistakes (CM) & 199 & 2.4091 & .77664 & 1.00 & 4.70 \\
Doubts about actions (DA) & 199 & 2.8546 & 1.87323 & 1.00 & 27.00 \\
Parental Expectations (PE) & 199 & 2.6596 & .72265 & .60 & 4.60 \\
Parental criticism (PK) & 199 & 1.9525 & .72035 & 1.00 & 5.00 \\
Maladaptive perfectionism (MAP) & 199 & 2.4392 & .55313 & 1.00 & 4.10 \\
Personal Standards (PS) & 199 & 3.2180 & .66422 & 1.57 & 5.00 \\
Organization (O) & 199 & 4.0361 & .69463 & 1.33 & 5.00 \\
Adaptive perfectionism (AP) & 199 & 3.6372 & .58655 & 1.79 & 5.00 \\
Tension & 199 & 2.2636 & .83554 & 1.00 & 5.00 \\
Depression & 199 & 1.6618 & .73488 & 1.00 & 5.00 \\
Anger & 199 & 1.7981 & .77138 & .72 & 5.00 \\
Vigor & 199 & 3.2754 & .84384 & .60 & 5.00 \\
Fatigue & 199 & 1.9873 & 1.18349 & .80 & 14.00 \\
Emotional calming (EC) & 199 & 3.2105 & .72882 & 1.00 & 5.00 \\
Active planning/ & 199 & 3.5224 & 1.01243 & 1.00 & 5.00 \\
Cognitive restructuring (CR) & 199 & 1.7609 & .64894 & 1.00 & 3.66 \\
Mental withdrawal (MW) & 199 & 1.9706 & .83686 & 1.00 & 4.00 \\
Behavioral risk (BR) & 199 & 2.1834 & 1.72398 & 1.00 & 22.00 \\
Seeking social support (SSS) & & & & &
\end{tabular}

One of the tasks of our research was to investigate how the researched individuals coped with the current situation of self-isolation and lack of normal sports-competitive and educational activities. Coping with this situation required regulation of emotions and changes in behavior and/or cognitions in order to manage the situation better. Coping strategies are especially important in the management of psychological stress related to harmful, threatening or challenging situations (Lazarus, 1999).

Active planning, Cognitive restructuring $(\mathrm{M}=3.52)$ and Emotional calming $(\mathrm{M}=3.21)$ were dominant in the sample we researched (Table 1). Athletes tried to get the positive out of the situation, to learn something new, to restructure their goals. They tried to block the negative thoughts, to keep their positive emotional state so that they could counter the problem and concentrate on important things. They showed a weaker proneness to Seeking social support
$(\mathrm{M}=2.18)$ from their coaches, psychologists, parents, friends to cope with the problem. Mental withdrawal $(\mathrm{M}=1.76)$ received the lowest score. This means they did not quit trying to achieve their goals, get reconciled with the situation nor did they refuse to be active.

It was interesting to find out whether there were cultural or national differences as regards perceiving, experiencing and coping with the situation imposed by the pandemic COVID-19. The comparative analysis along the factor nationality revealed significant cross-cultural differences (Table 2) as regards maladaptive perfectionism and its subscales - Concern over mistakes and Parental criticism, Adaptive perfectionism and its subscales - personal standards and organization, depression and vigor. There were statistically significant differences as regards three of the preferred coping strategies - Emotional calming, Cognitive restructuring and Seeking social support. 
Table 2. Results from the comparative analysis along the factor nationality

\begin{tabular}{lccccccccccc}
\hline & CM & PK & DAP & PS & O & AP & $\begin{array}{c}\text { De- } \\
\text { pres- } \\
\text { sion }\end{array}$ & Vigor & EC & CR & SSS \\
\hline $\begin{array}{l}\text { Chi- } \\
\text { Square }\end{array}$ & 7.646 & 12.223 & 11.153 & 12.146 & 22.043 & 23.271 & 17.812 & 32.942 & 7.872 & 8.546 & 20.307 \\
df & 2 & 2 & 2 & 2 & 2 & 2 & 2 & 2 & 2 & 2 & 2 \\
Asymp. & .022 & .002 & .004 & .002 & .000 & .000 & .000 & .000 & .020 & .014 & .000 \\
Sig. & & & & & & & &
\end{tabular}

a. Kruskal Wallis Test; $\quad$ b. Grouping Variable: Nationality

The researched Bulgarian students had nificant differences as regards Parental critihigher values for the adaptive and lower val- cism, Organization, Adaptive perfectionism, ues for the maladaptive perfectionism and Anger, Fatigue and Cognitive restructuring. more strongly expressed depression symptoms The researched Olympic competitors had the but were more motivated and energetic in the lowest values for Parental criticism, Anger current situation. The foreign students study- and Fatigue and the highest for Organization ing in Bulgaria and Russia showed the highest and Adaptive perfectionism. They most often values for maladapted perfectionism and con- resort to Cognitive restructuring as a coping cern over mistakes, and the weakest expressed strategy. The students with the lowest level depression symptoms. The cognitive strategies of qualification (competing in student and reEmotional calming and Cognitive restructur- gional tournaments) had the lowest values for ing were the most strongly expressed among Organization and Adaptive perfectionism and them.

The comparative analysis of the results the highest for Parental criticism, Anger, Fatigue and Cognitive restructuring. along the factor qualification revealed sig-

Table 3. results from comparative analysis along the factor qualification

\begin{tabular}{lcccccc}
\hline & PK & O & AP & Anger & Fatigue & CR \\
\hline Chi-Square & 13.574 & 21.596 & 14.373 & 9.737 & 11.504 & 15.443 \\
df & 4 & 4 & 4 & 4 & 4 & 4 \\
Asymp. Sig. & .009 & .000 & .006 & .045 & .021 & .004 \\
\hline
\end{tabular}

There were statistically significant differ- Anger, Cognitive restructuring and Seeking ences along the factor sport (Table 4) in four social support.

of the researched indicators - Organization,

Table 4. Results from the comparative analysis along the factor sport

\begin{tabular}{lcccc}
\hline & O & Anger & CR & SSS \\
\hline Chi-Square & 34.708 & 30.197 & 30.210 & 28.821 \\
df & 18 & 18 & 18 & 18 \\
Asymp. Sig. & .010 & .036 & .035 & .051 \\
\hline
\end{tabular}

The comparative analysis revealed signif- values for Parental Expectations and Anger, as icant gender differences along six of the re- a reaction to the current situation. searched indicators (Table 5). Men had higher 
Table 5. Results from the comparative analysis along the factor gender

\begin{tabular}{lcccccc}
\hline & PE & O & AP & Depression & Anger & SSS \\
\hline Mann-Whitney U & 3585.000 & 3585.000 & 3790.500 & 4140.000 & 4020.000 & 3313.500 \\
Wilcoxon W & 8535.000 & 8635.000 & 8840.500 & 9190.000 & 8970.000 & 8363.500 \\
Z & -3.373 & -3.373 & -2.856 & -2.016 & -2.293 & -4.048 \\
Asymp. Sig. (2-tailed) & .001 & .001 & .004 & .044 & .022 & .000 \\
\hline
\end{tabular}

The women from the researched sample the related self-isolation. had significantly higher values for Adaptive perfectionism, Organization. They tend to show depression symptoms more often and to seek social support in pandemic situation and
The results from the correlation analysis of the data revealed significant relations between the subscales of Perfectionism, Mood States and Coping strategies (Figure 1).

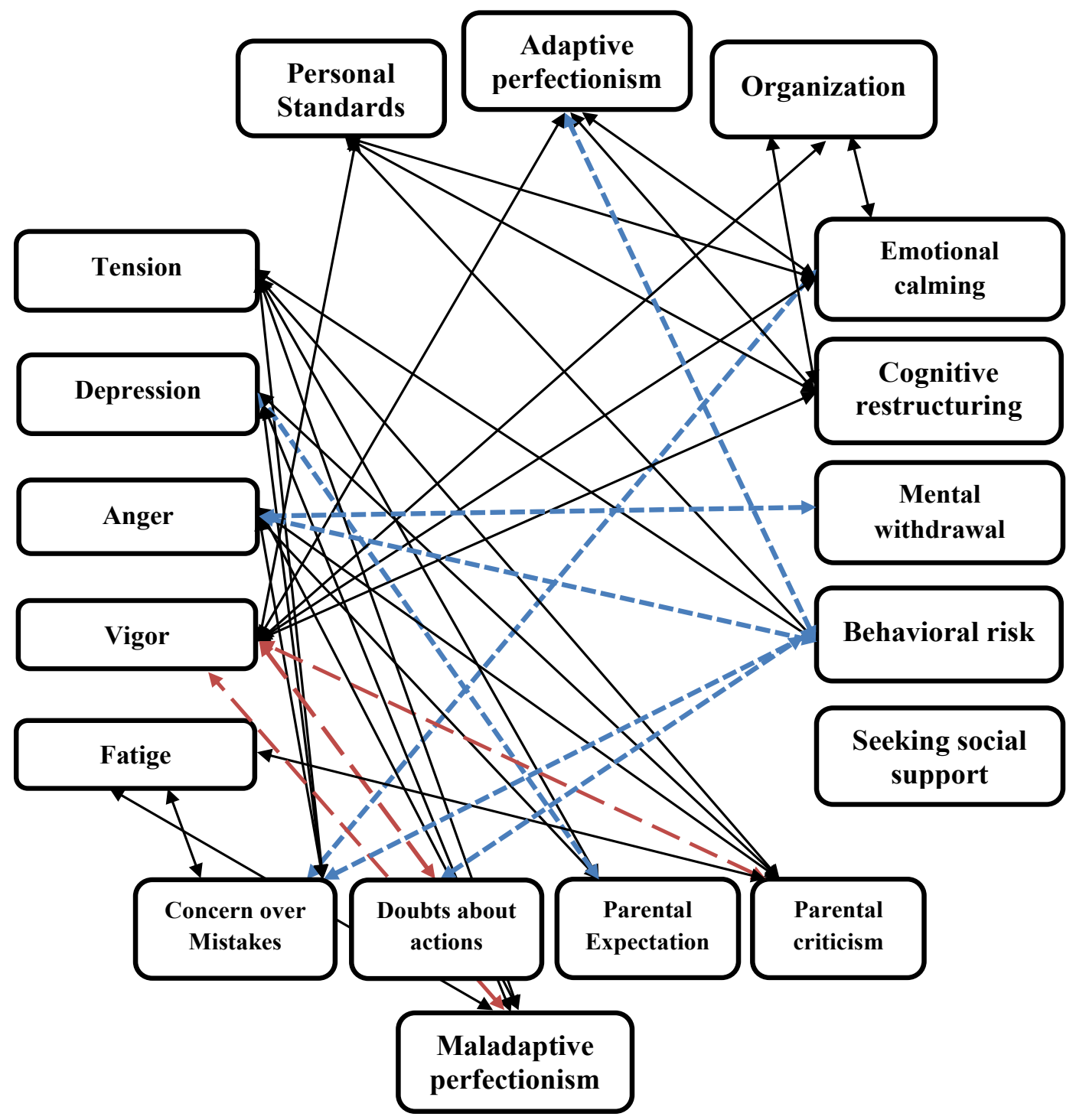

Legend: $\quad$ Significant positive correlations $(* *)$

- - - - - - - - Moderate correlations (*)

- - - - - Negative correlation

Figure 1. Results from correlation analysis 
We established significant correlation dependencies between Adaptive perfectionism and Emotional calming ( $r=.510 * *)$, Cognitive restructuring $\left(r=.454^{* *}\right)$ and Vigor $(r=.364 * *)$, between Personal Standards and Emotional calming $\left(r=.494^{* *}\right)$, Cognitive restructuring $\left(r=.436^{* *}\right)$ and Vigor $\left(r=.254^{* *}\right)$, between Organization and Emotional calming $\left(r=.400^{* *}\right)$, Cognitive restructuring $(r=.362 * *)$ and Vigor $(r=.309 * *)$.

There were significant positive correlations between Maladaptive perfectionism and the researched psychic conditions - Tension $\left(r=.418^{* *}\right)$, Depression $\left(r=.241^{* *}\right)$, Anger $(r=.354 * *)$, Fatigue $(r=.232 * *)$ and negative correlation with Vigor $(r=-.164 *)$. This trend was confirmed in the subscales of Maladaptive perfectionism. There were significant positive correlations among all subscales of Maladaptive perfectionism with Tension, Depression, Anger, Fatigue and negative correlation with Vigor (Figure 1). There were moderate correlations between Behavioral risk and Concern over Mistakes $\left(r=.148^{*}\right)$ and Doubts about actions $\left(r=.155^{*}\right)$.

Table 6. Results from Regression analysis
One of the tasks of our research was to clarify the role of perfectionism in the way one experiences a threatening, uncertain and risky situation, as in COVID-19, as well as the coping strategies used in such situation. The data from the correlation analysis revealed the specific role of perfectionism in its two forms - adaptive and maladaptive. While the scales of the adaptive perfectionism are related to Vigor and active constructive coping strategies (Figure 1), the scales of Maladaptive perfectionism are related mostly to negative experiences - Tension, Depression, Anger, Fatigue and lowering of Vigor, as well as elements of risky behavior.

To check this hypothesis, we applied a step regression analysis. In the first model, the independent variable was Adaptive perfectionism, and the dependent variables - strategies for coping with psychic conditions. The results from the regression analysis showed that the high levels of Adaptive perfectionism influenced strategies Emotional calming and Cognitive restructuring, Vigor and Tension (Table 6).

\begin{tabular}{lcccc}
\hline & Adaptive & Perfectionism & & \\
\cline { 2 - 5 } & $\boldsymbol{\beta}$ & $\boldsymbol{t}$ & $\mathbf{S i g}$. & $\mathbf{\Delta R}^{\mathbf{2}}$ \\
\hline Emotional calming & .329 & 4.374 & .000 & .257 \\
Vigor & .261 & 4.178 & .000 & .313 \\
Cognitive restructuring & .170 & 2.254 & .025 & .328 \\
Tension & .122 & 2.032 & .043 & .338 \\
\hline
\end{tabular}

In the second model, the independent variable was Maladaptive perfectionism. The results from the regression analysis showed that

Table 7. Results from Regression analysis

\begin{tabular}{ccccc}
\hline & Maladaptive & Perfectionism & Maladaptive & \\
\hline & $\beta$ & $\boldsymbol{t}$ & Sig. & $\Delta \mathbf{R}^{2}$ \\
\hline Tension & .418 & 6.467 & .000 & .171 \\
\hline
\end{tabular}

\section{DISCUSSION}

The pandemic COVID-19 has changed the usual life of the people all over the world and affected the field of sport very much. The emergency situation and the related to it situation of self-isolation posed serious ordeals to 
athletes - all competitions from the national and international calendars were postponed, including the biggest sporting event - the Olympic Games in Tokyo, 2020. From a life full of high physical activity, extensive travelling, competitions, strong emotions arising from sports-competitive activities, athletes had to adapt to living in an isolated environment without being able to practice their usual activities, having unclear prospects and experiencing fear of getting diseased. How do they react, how do they live, how do sports students cope with this situation - these are questions which are looking for solution on the basis of objective empirical data.

The results obtained from our research on domineering emotional states and perfectionism and their relation to sports students' preferred coping strategies in times of the pandemic COVID-19 revealed a certain specificity in the manifestation of the researched indicators depending on nationality, gender, qualification, and kind of sport.

Perfectionism is an important psychological variable which influences the way athletes' cognitive, affective, and behavior characteristics function (Davis, 1997; Frost, Heimberg, Holt, Mattia, \& Neubauer, 1993, Hamashek, 1998; Terry-Short, Owens, Slade, \& Dewey, 1995). Therefore, the fact that adaptive perfectionism and its subscales Organization and Personal Standards were domineering among the researched sports students is a positive finding. The lowest values were received for Parental criticism and Concern over Mistakes. The obtained results, as a whole, support previous finds (Iancheva, 2013).

We can summarize that the studied athletes on a cognitive and behavioral level use adequate strategy to overcome the situation.

The established fact that Vigor was domineering among the researched athletes is also positive. Having in mind that the research was conducted within 30-40 days after the start of the emergency situation, we can claim that the researched individuals were coping relatively well with the current situation. Regardless of the imposed lockdown and isolation, the researched athletes feel quite energetic, alert and motivated. Next is Tension, i.e. regardless of preserving a relative vitality and energy, the researched sports students experience nervousness, anxiety, agitation. The established fact that Depression had the lowest values is favorable.

The comparative analysis of the data revealed significant differences along the factors gender, kind of sport, qualification, and nationality.

The women in the researched sample had significantly higher values for Adaptive perfectionism, Organization. They are more prone to manifestation of depression symptoms and to seeking social support. The men had higher values for Parental Expectations and Anger, as a reaction to the imposed isolation. These results suppose different direction of the applied psychological interventions for coping with the situation.

We established significant differences depending on the qualification of the researched sports student as regards Parental criticism, Organization, Adaptive perfectionism, Anger, Fatigue and Cognitive restructuring. With the growth of sportsmanship (especially at the Olympic level) the strategy of cognitive restructuring, finding a constructively positive way to solve the problem becomes more important. The researched individuals with the highest qualification - competitors who have won quotas and are preparing for participation in the Olympic Games in Tokyo are coping with the situation the most successfully and are the most adaptive during the pandemic. They had the lowest values for Parental criticism, Anger and Fatigue and the highest for Organization 
and Adaptive perfectionism. They most often resort to Cognitive restructuring as a coping strategy. The students with the lowest level of qualification (competing in student and regional tournaments) had the lowest values for Organization and Adaptive perfectionism and the highest for Parental criticism, Anger, Fatigue and Cognitive restructuring. Our results confirm other research on the differences in coping strategies depending on the level of sportsmanship and successful realization in sports (Rogaleva, Malkin, et al., 2019).

The comparative analysis of the data along the factor nationality revealed significant cross-cultural differences along eleven of the researched indicators. This fact is of great practical importance. Planning and realization of psychological influences require taking into account the national and cultural peculiarities which affect the way of perception and experience of the consequences of the pandemic COVID-19, and the preferred coping strategies as well.

The results from the correlation analysis of the data revealed significant relations between the subscales of Perfectionism, Mood States and Coping strategies. Our results reveal the specific mediator role of perfectionism and its two forms - adaptive and maladaptive as regards the way one experiences a threatening, uncertain and risky situation, in this case - COVID-19, and the preferred coping strategies. The adaptive perfectionism and its subscales correlate with Vigor and active constructive coping strategies and in this way help the adaptive behavior. Maladaptive perfectionism is connected mainly with negative experiences - Tension, Depression, Anger, Fatigue and lowering of Vigor, as well as elements of risky behavior. In this sense, our results support the surveys of Enns \& Cox (2002) about the functional nature of the subscales Personal standards and Organization, as well as the role of maladaptive perfectionism and the subscales Concern over mistakes, Parental criticism, Parental expectations, and Doubts about actions as stimulating negative functioning.

The results of our study prove the advantage of adaptive perfectionism in a pandemic (or stressful situation), and this provides a basis for better understanding and psychological assistance to athletes in overcoming difficult situations and emotional states.

As part of our study, we obtained new data that prove the important role of adaptive perfectionism in overcoming stressful situations, in our case in a pandemic, at the expense of cognitive restructuring strategies and emotional calm, which allows to increase energy and seek the most the optimal solution to the problem.

According to the data from our study, foreign students are the most vulnerable, both in terms of more pronounced maladaptive perfectionism and in the choice of strategies for coping with the situation and more pronounced negative states.

The obtained results are a valuable reference point in seeking the most efficient approaches to athletes' coping with the consequences from the pandemic COVID-19 and considering their specifics depending on the gender, qualification, kind of sport, national and cultural peculiarities, especially because there are still few surveys on the subject. They can be useful to psychologists, coaches and educators in analyzing and understanding the impact of self-isolation on athletes' behavior and providing adequate psychological help and support.

\section{LIMITATIONS}

This research has a few limitations - the number of the researched sample and the fact it was carried out online. A wider scope of research would allow for a more in-depth analysis and interpretation. 


\section{REFERENCES}

Anshel, M. H. (1990). Toward validation of a model for coping with acute stress in sport. International Journal of Sport Psychology, 21, 58-83.

Anshel, M.H., Kim, K-W., Kim, B-H., Chang, K-J., \& Eom, H-J. (2001). A model for coping with stressful events in sport: Theory, application, and future directions. International Journal of Sport Psychology, 32(1), 43-75.

Arden, M.A.\& Chilcot, J. (2020). Health psychology and the coronavirus (COVID-19) global pandemic: A call for research. British journal of health psychology,25 (2), 231-232 DOI: 10.1111/bjhp.12414

Brannan, M., Petrie, T. A., Greenleaf, C., Reel, J., \& Carter, J. (2009). The relationship between body dissatisfaction and bulimic symptoms in female collegiate athletes. Journal of Clinical Sport Psychology, 3, 103-126.

Brooks, S. K. Webster, R.K., Smith, L.E. et al. (2020). The psychological impact of quarantine and how to reduce it: rapid review of the evidence. Lancet, 395, 10227, 912-920. DOI: 10.1016/S0140-6736(20)30460-8

Burns, D. D. (1980). Feeling good: The new mood therapy. New York: The New American Library Inc

Crocker, P., \& Graham, T. (1995). Emotion in sport and physical activity: The importance of perceived individual goals. International Journal of Sport Psychology, 26, 117-137.

Crocker, P.R.E., \& Isaak, K. (1997). Coping during competitions and training sessions: Are youth swimmer consistent? International Journal of Sport Psychology, 28, 355-369.

Crum, A. J., Akinola, M., Martin, A. \& Fath, S. (2017). The role of stress mindset in shaping cognitive, emotional, and physiological responses to challenging and threatening stress. Anxiety Stress Coping, 30,4, 379-395. DOI: $10.1080 / 10615806.2016 .1275585$

Crum, A. J., Salovey, P. \& Achor, S. (2013).
Rethinking stress: the role of mindsets in determining the stress response. Journal of personality and social psychology, 104, 4, 716733. DOI: 10.1037/a0031201 DOI: 10.1037 / a0031201

De la Fuente, J., Kauffman, D., Dempsey, M., Kauffman, Y. (2020). Coronavirus Disease (COVID-19): Psychoeducational Variables Involved in the Health Emergency. (n.d.). Retrieved May 20, 2020, from https://www.frontiersin.org/researchtopics/13709/coronavirus-disease-covid-19psychoeducational-variables-involved-in-thehealth-emergency

Domuschieva-Rogleva, G.D., Iancheva, T. (2017). Coping strategies for the participants in the Antarctic expedition. In: Revista de Psicología del Deporte, Vol 26, Suppl. 4, pp. 4550

Eaton, LA. \& Kalichman, SC. (2020). Social and behavioral health responses to COVID-19: lessons learned from four decades of an HIV pandemic. Journal of behavioral medicine. DOI: 10.1007/s10865-020-00157-y

Eklund, R., Gould, D., \& Jackson, S. (1993). Psychological foundations of Olympic wrestlingexcellence: Reconciling individual differences and nomothetic characterization. Journal of Applied Sport Psychology, 5, 36-47.

Ellemers, N. \& Jetten, J. (2013). The Many Ways to Be Marginal in a Group. Personality and social psychology review, 17, 1, 3-21. DOI: $10.1177 / 1088868312453086$

Enns, M. W., \& Cox, B. J. (2002). The nature and assessment of perfectionism: A critical analysis. In G. L. Flett \& P. L. Hewitt (Eds.), Perfectionism: Theory, research, and treatment (pp. 33-62). Washington: American Psychological Association.

Epel, E.S., McEwen, B.S. \& Ickovics, J.R. (1998). Embodying psychological thriving: physical thriving in response to stress. Journal of Social Issues, 54, 2, 301-322. DOI: 


\subsection{1/0022-4537.671998067}

Feldman, S. \& Stenner, K. (1997). Perceived threat and authoritarianism. Polit. PsychoL 18, 741-770

Filion, S., Munroe-Chandler, K. \& Loughead, T. (2019). Psychological Skills Used by Sport Psychology Consultants to Improve Their Consulting. International journal of sport and exercise psychology. DOI: 10.1080/10413200.2019.1647475

Flett, G. L., Hewitt, P. L. (2006). Positive versus negative perfectionism in psychopathology: a comment on Slade and Owens's dual process model. Behavior Modification, 30, 472-495.

Folkman, S. (1992). Making the case for coping. In B. Carpenter (Ed.) Personal coping: Theory, Research, and Application, 31-46, New York: Prager.

Folkman, S., R. Lazarus. (1980). An analysis of coping in middle - aged community sample. - In: Journal of Health and Social Behavior, No 21, 219-39.

Frontiers. Research Topic (2020). Coronavirus Disease (COVID-19): Psychoeducational Variables Involved in the Health Emergency. Retrieved on 20 May, 2020 from https://www. frontiersin.org/research-topics/13709/coronavirus-disease-covid-19-psychoeducationalvariables-involved-in-the-health-emergency

Frontiers. Research Topic (2020). Creativity and Innovation in Times of Crisis (COVID-19). Retrieved on 20 May 2020 from https:// www.frontiersin.org/research-topics/13833/ creativity-and-innovation-in-times-of-crisiscovid-19

Frontiers. Research Topic (2020). The Effects of the Covid-19 Pandemic on Sport: Mental Health Implications on Athletes, Coaches and Support Staff (2020). Retrieved from

Frost, Heimberg, Holt, Mattai, Neubauer (1993). A comparision of two measures of perfectionism. Personality and Individual dif- ferences, 14, 119-126.

Frost, R., \& Henderson, K.J. (1991). Perfectionism and reactions to athletic competition. Journal of Sport and Exercise Psychology, 13, 323-335.

Frost, R., Marten, P., Lahart, C., \& Roseblate, R. (1990). The dimensions of perfectionism. Cognitive Therapy and Research, 14, 449-468.

Gibson, J.L. (1996). With malice toward some: How people make civil liberties judgments -Marcus, GE, Sullivan, JL, TheissMorse, E, Wood, SL. American political science review, 90, 4, 916-917. DOI: 10.2307/2945883

Gould, D., Finch, L. M. \& Jackson, S. A. (1993). Coping stratrgies used by national champion figure skaters. Journal of Sport and Exercise Psychology, 15, 134-159.

Gould, D., Udry, E., Bridges, D., \& Beck, L. (1997). Coping with season - ending injuries. The Sport Psychologist, 11, 379-399.

Greenaway, K. H., Jetten, J., Ellemers, N. \& van Bunderen, L. (2015). The dark side of inclusion: undesired acceptance increases aggression. Group processes \& intergroup relations, 18, 2, 173-189. DOI: 10.1177/1368430214536063

Hall, H. K., Kerr, A.W., \& Matthews, J. (1998). Precompetitive anxiety in sport the contribution of achievement goals and perfectionism. Journal of Sport and Exercise Psychology,20, 194-217.

Hamachek, D. E. (1998). Psychodynamics of normal and neurotic perfectionism. Psychology, 15, 27-33.

Hazeldine, J., Arlt, W. \& Lord, J. M. (2010). Dehydroepiandrosterone as a regulator of immune cell function. Journal of steroid biochemistry and molecular biology, 120, 2-3, 127-136. DOI: 10.1016/j.jsbmb.2009.12.016

https://www.frontiersin.org/research-top$\mathrm{ics} / 14032 /$ the-effects-of-the-covid-19-pandemic-on-sport-mental-health-implications- 
on-athletes-coaches-and-sup\#overview

Huang, C., Wang, Y. \& Li, X. (2020). Clinical features of patients infected with 2019 novel coronavirus in Wuhan, China. Lancet, 395, 10223, 496-496. DOI: 10.1016/S01406736(20)30252-X.

Iancheva, T. (2009). Adaptaciq na Multidimensional Perfectionism Scale (MPS) na Frost, Marten, Lahart, \& Rosenblate (1990) za izsledwane na perfekcionizma $\mathrm{v}$ sporta, Lichnost, motivaciq, sport, T. 14, NSA PRES, 121-128 (In Bulgarian)// Янчева, Т. (2009). Адаптация на Multidimensional Perfectionism Scale (MPS) na Frost, Marten, Lahart, \& Rosenblate (1990) за изследване на перфекционизма в спорта, Личност, мотивация, спорт, Т. 14, НСА ПРЕС, 121-128.

Iancheva, T. (2013). Perfectionism, Goal orientation, and Self-Efficacy with elite Rhythmic gymnasts, The ISSP 13th World Congress of Sports Psychology.

Jacobi, F. (2020). Ride out domestic isolation and quarantine. Psychotherapeut. DOI: 10.1007/s00278-020-00424-y

Jamieson, J. P., Crum, A. J., Goyer, I. P., Marotta, M. E. \& Akinola, M. (2018). Optimizing stress responses with reappraisal and mindset interventions: an integrated model. Anxiety Stress Coping, 31, 3, 245-261. DOI: 10.1080/10615806.2018.1442615

Jetten, J., Haslam, S. A., Cruwys, T., Greenaway, K.H., Haslam, C. \& Steffens, N.K. (2017). Advancing the social identity approach to health and well $\square$ being: Progressing the social cure research agenda. European journal of social psychology, 47,7, 789-802. DOI: 10.1002/ejsp.2333

Jetten, J., Haslam, C, \& Haslam, S. A. (eds.) (2012). The Social Cure: Identity, Health and Well-being. (Psychology Press).

Lazarus, R. S. (1991). CognitAion and motivation in emotion. American Psychology, 46, 352-367.
Lazarus, R.S., \& Folkman, S. (1984). Stress, appraisal and coping. Springer.

MacIntyre, T., Green, J., Beckmann, J., Lane, A., Vaughan, R., Morris, R., Murphy, E., Kenttä, G., Van Raalte, J., Calogiuri, G. (2020). The Effects of the Covid-19 Pandemic on Sport: Mental Health Implications on Athletes, Coaches and Support Staff. (n.d.). Retrieved May 20, 2020, from https://www.frontiersin. org/research-topics/14032/the-effects-of-thecovid-19-pandemic-on-sport-mental-healthimplications-on-athletes-coaches-and-sup

Marcus, G. E., Sullivan, J. L., TheissMorse, E. \& Wood, S. L. (1995). With Malice Toward Some: How People Make Civil Liberties Judgments. (Cambridge Univ.Press).

Owen, L. (2020). Five ways the coronavirus is hitting women in Asia. BBC News. Retrieved May 20, 2020 from https://www.bbc. com/news/world-asia-51705199

Parker, W. D. (1997). An empirical typology of perfectionism in academically talented children. American Educational Research Journal, 34, pp. 545-562.

Parnell, D., Widdop, P., Bond, A. \&Wilson, R. (2020). COVID-19, networks and sport Managing sport and leisure. DOI: 10.1080/23750472.2020.1750100

Peters, E., Lipkus, I. \& Diefenbach, M. A. (2006). The functions of affect in health communications and in the construction of health preferences. /. Commun. 56, S140-S162

Rogaleva, L., Malkin, V. et al. (2019). Coping strategies and Mental Reliability as Psychological Determinants of Success in Sport. Proceedings of the 2019 International Conference on Pedagogy, Communication and Sociology (ICPCS 2019). DOI: 10.2991/ icpcs-19.2019.82

Sahu, P. (2020). Closure of Universities Due to Coronavirus Disease 2019 (COVID-19): Impact on Education and Mental Health of Students and Academic Staff. Cureus, 12, 4, 
e7541, 1-6 DOI: 10.7759/cureus.7541

Schinke, R., Papaioannou, A., Henriksen, K., Si, GY., Zhang, LW. \& Haberl, P. (2020). Sport psychology services to high performance athletes during COVID-19. International journal of sport and exercise psychology, 17, 269272. DOI: $10.1080 / 1612197 X .2020 .1754616$

Sokolowska, J., Ayton, P., Brandstätter E. (2020). Coronavirus Disease (COVID-19): Psychological Reactions to the Pandemic. (n.d.). Retrieved June 04, 2020, https://www. frontiersin.org/research-topics/13744/coronavirus-disease-covid-19-psychological-reactions-to-the-pandemic

Van Bavel, JJ., Baicker, K., Boggio, PS., Capraro, V. et al. (2020). Using social and behavioural science to support COVID-19 pandemic response. Nature human behaviour, vol.
4, 460-471. DOI: 10.1038/s41562-020-0884-Z

Wang, J., Wang, JX. \& Yang, G.S. (2020). The Psychological Impact of COVID-19 on Chinese Individuals. Yonsei medical journal, 61 (5), 438-440. DOI: 10.3349/ ymj.2020.61.5.438

Yancheva, M., Domuschieva-Rogleva, G. (2012). Strategies for coping with stress for judo competitors; In: Proceeding book XVI International Scientific Congress "Olympic Sports and Sport for All” and VI International Scientific Congress „,Sport, Stress, Adaptation” 17-19 May, Sport \& Science, Extra Issue, pp. $697-701$.

Zhou, K, et al. (2020). Clinical course and risk factors for mortality of adult inpatients with COVID-19 in Wuhan, China: a retrospective cohort study. Lancet 395, pp.1054-1062

\section{Corresponding author:}

Tatiana Iancheva

Department of "Psychology, pedagogy and sociology" National Sports Academy "Vassil Levski" 21 Acad. Stefan Mladenov Str. Sofia 1700, Bulgaria E-mail: iancheva.tatiana@gmail.com 